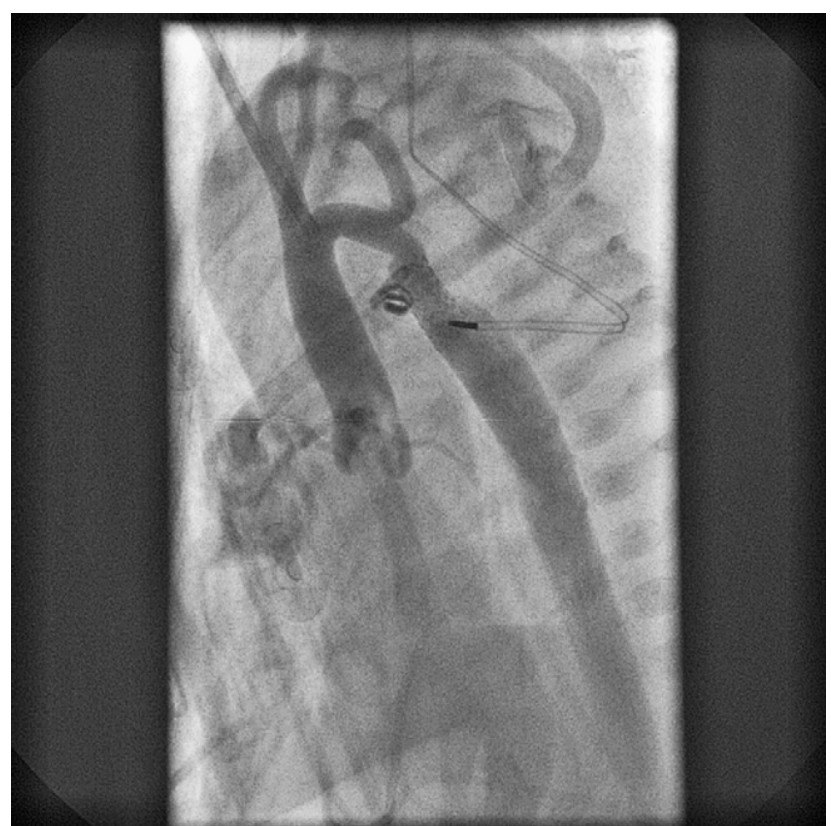

FIGURE 2. Angiogram after stent implantation demonstrating resolution of coarctation.

repair by means of resection with an extended end-to-end anastomosis. 4 We chose a staged hybrid approach with stent implantation for short-term repair of the coarctation, enabling us to stabilize the infant's blood pressure and improve end-organ perfusion. Given concerns over aortic disruption during stent implantation, the stent was inflated to a diameter not exceeding that of the native aorta. Additionally, we selected a short stent to allow for complete excision of the stent-containing aortic segment at the time of coarctation repair.
This case highlights the pitfalls associated with limited evaluation of preterm infants for ligation or medical treatment of what is typically assumed to be an isolated PDA. It also highlights that a collaborative approach with lowrisk therapy as a bridge can result in a highly successful outcome. Palliation in extremely preterm infants has typically been balloon angioplasty, with isolated reports of stent implantation in 3 preterm infants weighing more than $1 \mathrm{~kg}$ and infants of greater than 30 weeks gestation. ${ }^{6-9}$ To our knowledge, this is the first report of stent dilation of coarctation as primary treatment in a 28 -week 800 -g neonate. In our case stent implantation with a low-profile, premounted coronary stent proved to be a safe approach as a bridge to definitive repair and might be applicable in other selected patients.

\section{References}

1. Hornung TS, Benson LN, McLaughlin PR. Interventions for aortic coarctation. Cardiol Rev. 2002;10:139-48.

2. Sudarshan CD, Cochrane AD, Jun AH, Soto R, Brizard CP. Repair of coarctation of the aorta in infants weighing less than 2 kilograms. Ann Thorac Surg. 2006;82: 158-63.

3. Puchalski MD, Williams RV, Hawkins JA, Minich LL, Tani LY. Follow-up of aortic coarctation repair in neonates. $J$ Am Coll Cardiol. 2004;44:188-91.

4. Thomson JDR, Mulpur A, Guerrero R, Nagy Z, Gibbs JL, Watterson KG. Outcome after extended arch repair for aortic coarctation. Heart. 2006;92:90-4.

5. Bacha EA, Almodovar M, Wessel DL, Zurakowski D, Mayer JE, Jonas RA, et al. Surgery for coarctation of the aorta in infants weighing less than $2 \mathrm{~kg}$. Ann Thorac Surg. 2001;71:1260-4

6. Sutton N, Lock JE, Geggel RL. Cardiac catheterization in infants weighing less than 1,500 grams. Catheter Cardiovasc Interv. 2006;68:948-56.

7. Shamberger MA, Lababidi ZA. Successful balloon angioplasty of a coarctation in an infant <500 g. Pediatr Cardiol. 1998;19:418-9.

8. McMahon CJ, Alromani A, Nihill MR. Balloon angioplasty of critical coarctation in a 970-gram premature infant. Cardiol Young. 2001;11:468-71.

9. Radtke WA, Waller R, Hebra A, Bradley SM. Palliative stent implantation for aortic coarctation in premature infants weighting $<1,500$ g. Am J Cardiol. 2002;90:1409-12.

\title{
Innovative surgical technique of right upper bilobe transplantation
}

\author{
Federico Rea, MD, Abdel-Mohsen Hamad, MD, Monica Loy, MD, Cristiano Breda, MD, \\ Marco Schiavon, MD, and Giuseppe Marulli, MD, Padova, Italy
}

Thoracic surgeons involved in lung transplantation are faced with the problems of scarcity of available donors

\footnotetext{
From the Department of Cardiothoracic and Vascular Sciences, University of Padova, Padova, Italy.

Disclosures: None.

Received for publication Jan 28, 2009; accepted for publication April 11, 2009; available ahead of print June 1, 2009.

Address for reprints: Federico Rea, MD, Department of Cardiothoracic and Vascular Sciences, University of Padova, Via Giustiniani, 2, 35128, Padova, Italy (E-mail: federico.rea@unipd.it).

J Thorac Cardiovasc Surg 2010;139:1071-3

$0022-5223 / \$ 36.00$

Copyright (c) 2010 by The American Association for Thoracic Surgery

doi:10.1016/j.jtcvs.2009.04.008
}

and size mismatch between the donor lung and the recipient thoracic cage. Different size-reduction techniques or resection of localized pathology limited to 1 lobe allows tailoring of the grafted lung to the size of the thoracic cage and increasing the donor pool. ${ }^{1}$ We present an innovative technique of size reduction by a right lower lobectomy with the creation of a single bronchial stump for anastomosis.

\section{CLINICAL SUMMARY}

Double-lung transplantation was planned for a 63 -yearold woman with idiopathic pulmonary fibrosis. The matched donor was in a car accident and had a contusion of the right 

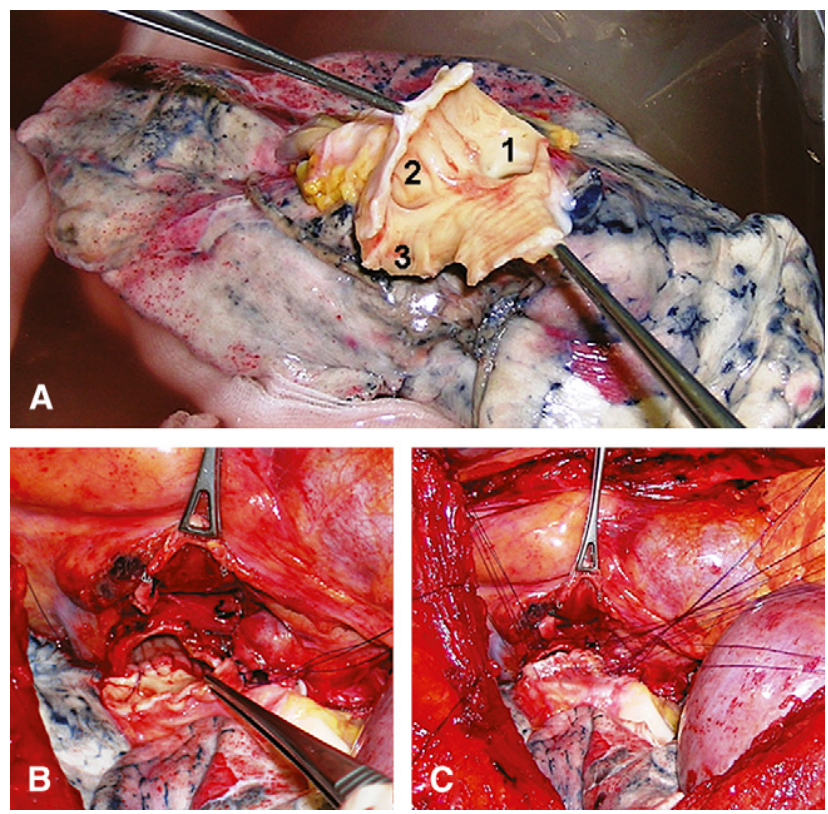

FIGURE 1. A, The donor right upper bilobe with the bronchus opened: 1 , upper lobe bronchus; 2, middle lobe bronchus; 3, divided lower lobe bronchus. B, Intraoperative view of bronchial anastomosis; the membranous part was completed. C, Intraoperative view of bronchial anastomosis after application of all sutures.

lower lobe. On pretransplant size matching, the predicted total lung capacity of the donor was $20 \%$ greater than the real total lung capacity of the recipient. We started with implantation of the left lung, and after inflation of the transplanted left lung, its oversize in comparison with the pleural space was confirmed; therefore, a peripheral segmental resection was required at the end of implantation of the second lung. On the recipient side, a right pneumonectomy was performed in a routine manner; however, the bronchus was divided obliquely to provide a larger stump for anastomosis. Simultaneously, on the back table, a lower lobectomy of the donor right lung was commenced. With the lung still partially inflated, the oblique fissure was dissected and com- pleted with a surgical stapler; the pulmonary artery was exposed in the fissure, and branches to the lower lobe were doubly ligated and divided, followed by stapling and division of the inferior pulmonary vein. The lower lobe bronchus was divided, and the proximal end was kept opened. The right main bronchus was also divided near the origin of the upper lobe bronchus, and this stump again was kept opened. The bronchus holding the upper bilobe was incised longitudinally at the medial cartilaginousmembranous junction (Figure 1,A), and the edges were gently trimmed to adapt to the recipient stump. Anastomosis was started by suturing the membranous edge of the donor bronchus intermedius to the membranous part of the recipient bronchus using a single running suture of 4-0 polydioxanone (Ethicon, Somerville, NJ) (Figure 1, B). The cartilaginous parts of both bronchi were anastomosed with interrupted 4-0 polydioxanone sutures (Figure 1,C). The completed anastomosis was checked intraoperatively with bronchoscopy for patency of the lobar bronchi and saline test for air leakage. Excess pericardial tissue at the hilum of the donor lung was used to cover the bronchial anastomosis. Arterial and venous anastomoses were performed. Postoperative chest $\mathrm{x}$-ray showed expanded lung parenchyma (Figure 2, A); transesophageal echocardiography confirmed a patent vascular anastomosis without distortion. Follow-up bronchoscopy showed an intact, patent airway with proper healing (Figure 2,B).

\section{DISCUSSION}

Patients with pulmonary fibrosis usually have reduced thoracic cavity, and exact size matching with a donor lung is difficult and may prolong the waiting list time. At the same time, an oversized transplanted lung is more prone to atelectasis, infection, and distortion of anastomosis; moreover, mediastinal compression may occur. Multiple sizereduction methods have been applied (including peripheral nonanatomic wedge resection, lobectomy, lobar, and splitlung transplantation) to adapt the grafted lung to the recipient thoracic cavity. ${ }^{1-4}$
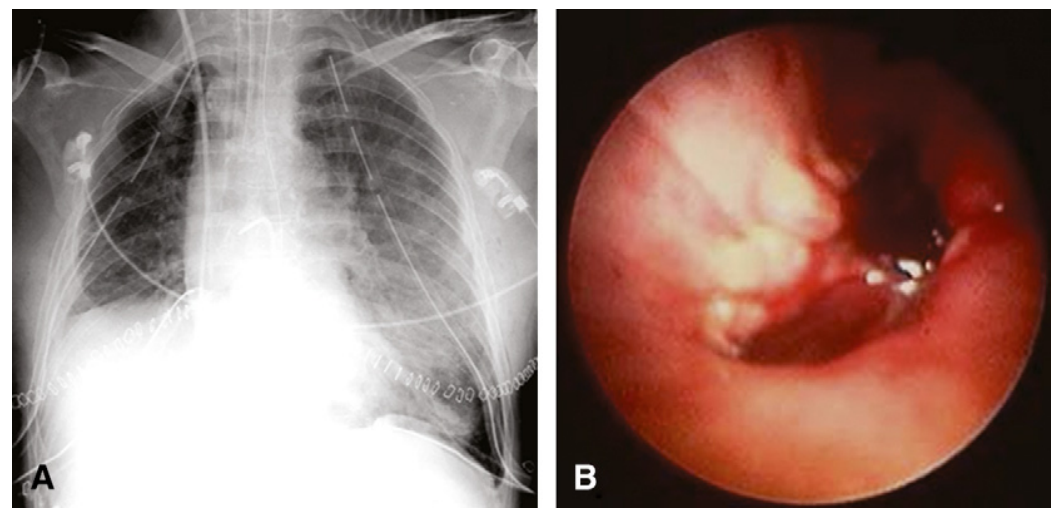

FIGURE 2. A, Postoperative chest radiograph showing right lung expansion. B, Follow-up bronchoscopy showing patent lobar bronchi and intact anastomosis. 
On the right side, size reduction usually involves peripheral wedge resection or middle or upper lobectomy, but not lower lobectomy. For anatomic reasons, the right lower lobe is more vulnerable to atelectasis, accumulation of secretions, and infections; this represents a common finding in a donor with a long intubation period. Thus, when a donor is marginal because of a compromised right lower lobe with expected size mismatch and necessity of a size-reduction procedure, the lung is either discarded or the size reduction will be at the expense of the healthier upper and middle lobes.

It is well known that postlobectomy bronchopleural fistula is more frequent after lower lobectomy than other types of resection. ${ }^{5}$ This may be due to the dependent position of the bronchial stump with more exposure to secretions and decreased retrograde blood flow from the surrounding lung parenchyma. In transplant recipients, the situation is further compromised with the use of immunosuppressive drugs, corticosteroids, and, possibly, prolonged mechanical ventilation. Consequently, the presence of 2 bronchial suture lines in a transplant recipient is a real threat. This may be the reason to avoid performing a lower lobectomy to reduce the size of the donor lung. With our technique, we avoided the pres- ence of 2 bronchial suture lines, a dependent bronchial stump, and the risk of postlobectomy bronchopleural fistula.

\section{CONCLUSIONS}

We consider this technique an addendum to the armamentarium of thoracic surgeons as a size-reduction procedure and a method of increasing the pool of donor lungs.

\section{References}

1. Aigner C, Mazhar S, Jaksch P, Seebacher G, Taghavi S, Marta G, et al. Lobar transplantation, split lung transplantation and peripheral segmental resection-reliable procedures for downsizing donor lungs. Eur J Cardiothorac Surg. 2004;25: 179-83.

2. Santos F, Lama R, Alvarez A, Algar FJ, Quero F, Cerezo F, et al. Pulmonary tailoring and lobar transplantation to overcome size disparities in lung transplantation. Transplant Proc. 2005;37:1526-9.

3. Couetil JP, Tolan MJ, Loulmet DF, Guinvarch A, Chevalier PG, Achkar A, et al. Pulmonary bipartitioning and lobar transplantation: a new approach to donor organ shortage. J Thorac Cardiovasc Surg. 1997;113:529-37.

4. Artemiou O, Birsan T, Taghavi S, Eichler I, Wisser W, Wolner E, et al. Bilateral lobar transplantation with the split lung technique. J Thorac Cardiovasc Surg. 1999; 118:369-70.

5. Sirbu H, Busch T, Aleksic I, Schreiner W, Oster O, Dalichau H. Bronchopleura fistula in the surgery of non-small cell lung cancer: incidence, risk factors, and management. Ann Thorac Cardiovasc Surg. 2001;7:330-6.

\title{
Two-stage operation for an extensive infected aortic arch
}

\author{
Masakazu Nakao, MD, MRCS, Yeong Phang Lim, MBBS, FRCS, FAMS, Martin John Jarmin III MD, \\ Boon Hean Ong, MBBS, MRCS, and Yeow Leng Chua, MBBS, FRCS, FAMS, Singapore
}

The optimal management of an extensive infection involving the aortic arch is not well defined. We report the use of a 2-stage operation that consists of an ascending aorta-descending aorta bypass through a median sternotomy followed by a total exclusion of the infected aortic arch with debridement of infected tissue through a left posterolateral thoracotomy.

\section{CLINICAL SUMMARY}

A 68-year-old man with hypertension and diabetes mellitus presented with fever associated with dysphagia and

\footnotetext{
From the Department of Cardiothoracic Surgery, National Heart Centre, Singapore. Disclosures: None.

Received for publication Feb 1, 2009; revisions received April 16, 2009; accepted for publication April 30, 2009; available ahead of print June 15, 2009.

Address for reprints: Masakazu Nakao, MD, MRCS, National Heart Centre, Singapore, Department of Cardiothoracic Surgery, Mistri Wing, 17 Third Hospital

Ave, Singapore 168752 (E-mail: masakazu.nakao@singhealth.com.sg).

J Thorac Cardiovasc Surg 2010;139:1073-5

$0022-5223 / \$ 36.00$

Copyright (C) 2010 by The American Association for Thoracic Surgery

doi:10.1016/j.jtcvs.2009.04.038
}

hoarseness of voice, as well as chest pain radiating to the back for a week. Computed tomographic analysis of the thorax revealed a distal aortic arch pseudoaneurysm $7.3 \mathrm{~cm}$ in diameter and air within the aortic wall (Figure 1). Blood cultures grew Salmonella enteriditis.

The patient underwent emergency surgical intervention. Intraoperatively, the pseudoaneurysm was also noted to involve the proximal aortic arch, including the roots of all 3 major branches. An ascending aorta-descending aorta bypass through a median sternotomy was performed to exclude the aortic arch and the proximal descending thoracic aorta. The left common femoral artery, right brachiocephalic artery, and right atrium were cannulated. The heart was displaced superiorly out of the pericardium by using the Urchin heart positioning device (Medtronic, Inc, Minneapolis, Minn) with full cardiopulmonary bypass, and the distal descending aorta was accessed through a longitudinal incision in the posterior pericardium. A $20-\mathrm{mm}$ woven Dacron graft was anastomosed to the distal descending thoracic aorta in a side-to-end fashion. The graft was tunneled proximally posterior to the inferior vena cava and brought up to 